\title{
Comunicação motriz nos jogos populares: uma análise praxiológica
}

\author{
Leys Eduardo dos Santos Soares* \\ Pierre Normando Gomes da Silva** \\ João Francisco Magno Ribas ${ }^{* * *}$
}

\begin{abstract}
Resumo: Este artigo tem como objetivo, a partir da Praxiologia Motriz, revelar as diferentes interações (comunicação, contracomunicação, gestemas e praxemas) presentes nos jogos sociomotrizes populares, praticados nas ruas e praças na cidade de João Pessoa-PB. Neste estudo, o jogo se revela como um ato de comunicação humana, por meio das ações corporais dos jogadores que criam e mantém um sistema complexo de interação, se revelando como uma fonte de aprendizagem de comunicação corporal, estratégias cognitivas e experiência cultural.
\end{abstract}

Palavras-chave: Jogos tradicionais. Comunicação. Praxiologia Motriz.

\section{INTRODUÇÃo}

O conhecimento Praxiológico, desenvolvido por Pierre Parlebas (2001), se constitui na "Ciência da Ação Motriz". Este pesquisador francês tem se dedicado a construir instrumentos de análise de jogos e esportes que permitem conhecer a gramática dessas manifestações. $O$ ponto de partida são as regras de funcionamento que elucidam as relações entre ação motriz, situação motriz e conduta motriz; permitindo o desvelar da sua lógica interna. De modo que essa

\footnotetext{
*Graduando em EF-DEF/UFPB. E-mail: leyseduardo@hotmail.com

**Professor no DEF/UFPB. E-mail: pierrenormandogomesdasilva@gmail.com

***Professor Adjunto da Universidade Federal de Santa Maria. E-mail: ribasjfm@uol.com.br
} 
ciência estuda a lógica interna dos jogos e esportes a partir das suas regras ou normas de funcionamento. A função desta análise é desvelar o mundo lúdico a partir das ações motrizes que são realizadas nos jogos e esportes. As ações de jogo acontecem como um sistema em que vários componentes interagem entre si e que qualquer mudança nas características desses componentes modifica toda a dinâmica do sistema, ou seja, altera sua lógica interna (OLIVEIRA; RIBAS, 2010).

Pela praxiologia motriz, os jogos e esportes poderão ser compreendidos por aspectos interacionais, no caso dos jogos sociomotrizes, onde a participação dos jogadores tem como essência, o ato de comunicação e/ou contracomunicação humana, nos quais os participantes interpretam a todo instante, mensagens de companheiros e/ou adversários.

No esporte institucionalizado, uma partida/jogo pode se tornar um espetáculo, devido à busca extrema por melhores resultados, subjetivando o funcionamento de qualquer jogo sociomotriz. A comunicação práxica constitui no elemento essencial do desenvolvimento e entendimento dos esportes sociomotrizes, pois são esses aspectos que orientam as decisões e melhores formas de realização das ações motrizes.

Estabelecer uma eficiente comunicação práxica desenvolvendo elementos de interação entre os companheiros e estratégias de contracomunicação motriz, torna uma equipe mais ofensiva. Ou seja, um jogador de futebol, por exemplo, terá um desempenho esportivo excelente quando desenvolve corretamente as ações motrizes (técnica) e quando entende das relações estabelecidas no jogo: proposta de jogo definida pelo treinador, sua função individual e coletiva, as combinações ofensivas e defensivas (comunicação), a interpretação e leituras de jogo (contracomunicação) consensuais para o grupo.

A Comunicação Práxica caracteriza-se pela estratégia motriz dos participantes, sendo ela que define as interações numa situação de jogo. Nos jogos de cooperação e oposição, um jogador não consegue atuar no campo de jogo sozinho por muito tempo. É 
necessário criar uma estratégia de interação motriz para alcançar os objetivos do jogo, e para isso, é essencial essa comunicação. Parlebas (2001) descreve-a a partir de duas categorias: a Comunicação Práxica Direta (Comunicação e Contracomunicação) e a Comunicação Práxica Indireta (Gestemas e Praxemas). Desta forma, é possível caracterizar o comportamento dos participantes analisando suas estratégias de colaboração e oposição, bem como, o entendimento da lógica interna do jogo. Passes e assistências são exemplos de ações de comunicação motriz, em que os companheiros se comunicam por meio de passes para alcançar um objetivo.

A Contracomunicação motriz é produzida pelos adversários para interceptar estas ações, criando estratégias (produção de Gestemas e Praxemas) para que o objetivo seja alcançado. O Gestema é a comunicação entre os companheiros da mesma equipe por meio de gestos codificados (movimentação de braços e mãos e olhares), com o fim de transmitir uma indicação de ordem tática ou relacional. $\mathrm{O}$ Praxema corresponde a conduta motriz interpretada como um signo, se constituindo no próprio comportamento observável de um jogador, sua leitura corporal, como desmarques, arremessos, deslocamentos, chutes, ações de defesa ou ataque em jogos coletivos (PARLEBAS, 2001).

O conhecimento praxiológico classifica os jogos e esportes de acordo com a sua Situação Motriz, a partir do modo como as ações são regidas e praticadas. E por estas situações, são chamadas por Parlebas (2001) de Situação Ludomotriz. Os jogos e esportes são assim classificados em quatro grandes categorias:

a) Esporte: caracterizado por possuir regras institucionalizadas, ou seja, há uma instituição, órgão ou federação que rege a sua prática. São exemplos, o Futebol, Basquete, Voleibol e outros semelhantes;

b) Quase Esporte: é o jogo semi-institucionalizado, aquele que ainda não possui um órgão (federação ou semelhante) que o gerencie. São atividades que têm as características de um esporte (local adequado para a prática, materiais específicos eespectadores), como por exemplo: Paintball e Jogo de dardos. 
c) Jogo Tradicional: é uma atividade não institucionalizada. Não há um órgão que determine suas regras, portanto são passíveis de alterações. O objetivo é a recreação, o prazer de jogar. Não se sabe bem ao certo a origem de muitos dos jogos tradicionais, o certo é que eles estão enraizados em uma larga tradição cultural (PARLEBAS, 2001). Em um mundo tecnológico, de jogos virtuais que mexem com todo imaginário infantil, a cultura do jogo tradicional ainda resiste e alguns jogos, como o baleado, são facilmente observados pelas ruas e praças da cidade. Abandonar estas práticas não significa apenas um enfraquecimento cultural, mas a extinção de uma cultura de movimento (ELLOUMI; PARLEBAS, 2009).

d) Quase Jogo Esportivo: são atividades livres que não seguem as regras do jogo, muitas vezes praticados para o próprio divertimento, sem importância de regras ou fins lucrativos, como por exemplo, o Paraquedismo, Mountain Bike e Alpinismo.

Sendo assim, o objetivo desse estudo consiste em distinguir as diferentes formas de Comunicação Motriz (contracomunicação motriz, gestemas e praxemas) contidas nos jogos de Travinha, Baleado e Futevôlei. Ao verificarmos a capacidade comunicativa dos jogadores e a qualidade tática destes jogos populares estaremos desvendando seu contexto cognitivo e cultural. Estes jogos foram selecionados por terem sido os jogos sociomotrizes mais praticados nas ruas e praças do bairro do Rangel na periferia de João Pessoa$\mathrm{PB} /$ Brasil.

\section{Metodologia}

Trata-se de uma pesquisa descritiva, para tornar evidente a lógica de funcionamento de jogos populares realizados no município de João Pessoa-Paraíba-Brasil. Durante a pesquisa, foram observados diferentes jogos nas ruas e praças do bairro do Rangel em João Pessoa, nos meses de janeiro a fevereiro de 2011, férias escolares. João Pessoa, fundada em 1585, possui uma população de 733,154 mil pessoas (CENSO, 2010), é a capital do estado da Paraíba, uma das melhores de qualidade de vida da Região Nordeste do Brasil. 
Possui diversos locais que favorecem a obtenção da vida saudável: praças planejadas para atividade física e com disponibilidade de aparelhos de ginástica, ciclovias, ruas fechadas para caminhadas matinais. É conhecida como "porta do Sol" devido sua localização e possuir o ponto mais oriental das Américas. O bairro do Rangel, é um dos 65 bairros desta cidade, localiza-se na Zona Oeste, faz divisa com o Jardim botânico, possui problemas ambientais. Por fazer fronteira com o bairro do Cristo, segundo mais populoso e terceiro maior colégio eleitoral, possui uma Associação Comunitária conjunta e fruto das reivindicações tem recebido incentivo às tradições locais (musicalidade carnavalesca) e a prática do esporte (corrida de rua e lutas), muito das praticas esportivas ou culturais acontecem na maior praça do bairro (Praça da Amizade), onde inclusive foi observado os jogos de futevôlei aqui analisados.

Ao focarmos nos jogos tradicionais, deixamos num segundo plano, os esportes massificados, como futsal e voleibol, que também são praticados no bairro. Foram observados 10 jogos de travinha em um terreno baldio do bairro. Este jogo era sempre praticado todos os dias da semana, sempre ao final da tarde e, a cada dia, eram diferentes adolescentes que participavam do jogo.

As observações que quase sempre aconteceram durante os fins de semana. No terreno baldio em que aconteciam os jogos de travinha havia um revezamento de grupos de jovens. Este terreno, de aproximadamente 10 metros de largura por 30 de comprimento, fica localizado em uma área de divisão entre dois bairros, no caso o bairro do Cristo e o do Rangel. E como não há outro espaço livre para se jogar travinha nos dois bairros, jovens revezavam o espaço durante os fins de semana para divertirem-se. Entre eles havia este consentimento. Por exemplo: nos sábados à tarde o terreno era da turma do Rangel, e no Domingo a tarde era da turma do Cristo.

Também observamos 8 jogos de futevôlei na quadra de vôlei de areia na Praça da Amizade e, sendo os praticantes moradores das redondezas. Além de 3 jogos de baleado na rua não pavimentada, praticado por crianças que residem na mesma. As observações foram 
realizadas sempre aos finais de tarde, dedicamo-nos a cada dia observar um jogo diferente, por cerca de duas horas.

A observação direta ocorreu a partir de um protocolo desenvolvido para descrever as interações motrizes nos jogos com as seguintes categorias: comunicação motriz, contracomunicação motriz, gestemas e praxemas. Este protocolo ficou assim estruturado:

1- Observações quanto às ações motrizes de Contracomu-nicação

a) Movimentação ofensiva adversária: observação das leituras antecipadas dos jogadores quanto às características do jogo adversário;

b) Movimentação defensiva: descrição das diferentes estratégias de contracomunicação para interceptar as ações de comunicação;

c) Protagonistas do jogo: observação do adversário que tem melhores habilidades com a bola, análise de suas preferências e apontamentos de erros a serem explorados pela equipe que está defendendo.

2-Observações quanto às ações motrizes de comunicação

a) Passes: descrição dos principais passes como meios mais visíveis e freqüentes de comunicação motriz entre os companheiros;

b) Movimentação ofensiva: descrição da movimentação de ataque como estratégia de jogo.

3- Observações quanto aos códigos gestêmicos e praxêmicos

Códigos Gestêmicos:

a) $\mathrm{O}$ olhar, distinção dos principais modos de olhar na Comunicação e Contracomunicação;

b) Linguagem das mãos, descrição dos principais movimentos de mão nas jogadas. 
Códigos Praxêmicos:

a) A movimentação, descrição dos tipos de movimentação que informam suas intenções aos companheiros e adversários;

b) Aindução corporal, descrições das principais formas de como os participantes induzem corporalmente um jogador adversário a cometer erros, "finta".

\section{Resultados e discussão}

\subsection{JOGO DE TRAVINHA}

Uma bola, um espaço livre e duas balizas - formadas muitas vezes por pedras, paus ou sandálias. Este jogo é o mais praticado nas ruas e praças do bairro do Rangel em João Pessoa-PB. A travinha é um mini-futebol jogado por: crianças, jovens e adultos. Diversas técnicas e gestos do futebol são reproduzidas/os durante o jogo. Mas, não assume as características de um esporte. Têm regras, mas estas são flexíveis, havia mudanças, por exemplo, no número de jogadores (3 ou mais), forma de realizar o lateral (só com a mão ou só com o pé), tempo de jogo (10` ou 2 gols), implemento (tamanhos de bolas). Não existe um árbitro, mas sim os árbitros-jogadores. Este jogo mantém as características do esporte futebol, daí chamarse Futebol de Travinha, mas sofrem muitas variações locais, portanto pode ser classificado, nas categorias de Parlebas (2001) de Jogo Tradicional ou jogo esportivo não institucionalizado, porque realizamse com regras válidas apenas localmente, cada comunidade joga a sua maneira e admite certa improvisação.

A seguir faremos uma análise praxiológica do jogo da travinha praticado por jovens com idades entre 12 e 17 anos em um terreno com 10 metros de largura por 30 de comprimento, com a baliza feita de pedaços de pernas de cadeiras, medindo 1,5 metros de largura e menos de um metro de altura, com linhas laterais marcadas na areia com o pé, delimitando o campo. 


\subsubsection{Ações Motrizes de Contracomunicação}

a) Movimentação ofensiva adversária: Se refere às principais características dos atacantes, em termos de estratégia de jogada, como por exemplo: identificar a perna dominante. Geralmente é essa que conduz a bola, assim, logicamente, será essa a perna de chute, ou seja, se for a perna direita, ele tem mais facilidade de se livrar da marcação pelo lado direito. Então, o jogo do adversário será de maior marcação pelo lado direito. Estas informações, pela contracomunicação, são detectadas nos primeiros minutos de jogo, nos primeiros contatos do adversário com a bola. A velocidade de deslocamento com a bola é outro fator observado pelos adversários, que antecipadamente, planejam ações e estratégias motrizes para impedir que o jogador veloz se desloque livremente com a bola, daí se faz a marcação individual para não dar espaço ao adversário.

b) Movimentação Defensiva: Um fator decisivo para uma ação defensiva é a análise da movimentação dos atacantes. No jogo de travinha foi observado três tipos de movimentações: Em Pivô, na qual um jogador ao centro distribui passes para seus companheiros avançarem pelas laterais, buscando o momento oportuno para infiltração (SAAD; COSTA, 2005). Em Linha, na qual dois jogadores ficam mais à frente participando do ataque e se movimentando na mesma linha. Em Alternância de posições, em que os três jogadores participam do ataque trocando de posições (ala e pivô) a todo o momento, na tentativa de confundir a marcação adversária, abrindo espaços para o chute (SAAD; COSTA, 2005).

A partir desta compreensão analítica das estratégias do jogo adversário, começa o processo de criação de contracomunicação para impedir as movimentações adversárias, a exemplo da marcação do pivô, impedindo que ele avance livremente e os demais fechando a extensão do gol. Neste sistema de marcação, os riscos são calculados, até quando nenhum jogador defensor se preocupa com a cobertura dos adversários. Pois, não se faz uma marcação individual, se faz uma alternância de posições, interferindo na qualidade do ataque adversário, caracterizando-se, segundo Saad e Costa (2005), como uma "marcação passiva". Em que os defensores não procuram 
roubar a bola do adversário, mas observam o que ele vai fazer, com o objetivo de apenas cercá-lo. Assim, num ataque de travinha, a equipe vai executando formas de oposição dentro do jogo, por meio de uma riqueza de interações.

c) Protagonistas do Jogo: os jogadores mais habilidosos estão sempre mais à frente, tentando roubar a bola. Geralmente são os que dão ritmo ao jogo, tornando-o mais rápido e competitivo. Quando estão de posse da bola, o comportamento dos adversários e companheiros fica totalmente diferente do habitual, pois eles têm um domínio tal em relação à bola, que esta "o procura, reconhece, precisa dele" (GALEANO, 2008, p.13). São estes jogadores que definem as jogadas, o que faz deles uma referência para com os companheiros e uma preocupação para os adversários, que mobiliza contra ele toda a defesa.

\subsubsection{AçõEs MOtRIZES DE COMUNICAÇÃO}

a) Passes: uma das formas de comunicação mais simples, visível e repleta de significados é o passe. O simples ato de passar a bola para o companheiro envolve objetivo e estratégia determinada por aquele que passou a bola, ninguém toca a bola só por tocar. Toda troca de passes tem uma razão, uma estratégia motriz está por trás, mesmo que, muitas vezes, o atleta queira apenas se livrar da posse de bola. Esta ação motriz é resultante da percepção, de que se permanecer por mais tempo em posse de bola, poderá perdê-la para o adversário. Toda a ação de passar a bola para o companheiro é uma comunicação que precisa ser interpretada por aquele que recebeu. Aquele que passa a bola tem uma estratégia motriz planejada, pois ele está convidando o companheiro para fazer parte da sua estratégia de jogo. O passe é um convite para a interação, que pode ser aceito ou simplesmente ignorado, ele está condicionado à situação de jogo, e depende principalmente dos adversários, pois, se eles estiverem próximos, há maior nível de troca de passes e interações.

b) Movimentação Ofensiva: A movimentação Em Pivô é muito utilizada para 'empurrar' o adversário para o meio da quadra quando 
este estiver marcando pressão. (SAAD; COSTA, 2005). O objetivo é fazer com que ele seja marcado por um jogador, deixando desta forma, as laterais livres para os outros dois companheiros se deslocarem. Esta ação motriz se caracteriza como um praxema, ele está dizendo para os companheiros que os dois devem se deslocar pelas as laterais do campo sem falar.

Quando os jogadores atacam Em Linha, a partir do momento em que se deslocam com a bola mais para direita ou mais para esquerda, ele está corporalmente dizendo para o companheiro que ele deve se deslocar para o outro lado e o acompanhar na mesma linha, para que ele o tenha na sua visão de jogo.

Na Alternância de Posições, os jogadores tentam deslocar a defesa adversária por um sistema de troca de posições em "V", objetivando criar espaços para o chute."Neste padrão, a equipe consegue envolver a defesa adversária e abrir espaços para possíveis infiltrações, além de ser indicado para valorizar a posse de bola" (SAAD; COSTA, 2005, p. 43). Na maioria dos jogos, a marcação é individual, por isso, alternar as posições dentro do campo adversário significa quebrar as estratégias defensivas. Nesta estratégia de todos atacarem reduzindo o espaço de contracomunicação, eles estão não só atacando mais defendendo ao mesmo tempo.

\subsubsection{Códigos Gestêmicos e PraXÊmicos}

\subsubsection{Códigos GestÊmicos}

a) O Olhar: a travinha é um jogo caracterizado por um espaço de pequenas dimensões, por isso mesmo com grande probabilidade de interceptação. E como é possível a comunicação por fala e gestos, a troca de olhares é intensa durante todo o jogo, os jogadores trocam mais olhares do que passes. O olhar é o elemento decisivo de uma ação ofensiva eficiente, já que na travinha os lançamentos em profundidade ou cruzamentos pelo alto é algo inviável. A maioria dos passes é efetuada a menos de 10 metros de distância. Seja em um escanteio, lateral ou uma simples troca de passes, o olhar define o local onde a bola será lançada, define para onde os companheiros 
devem se deslocar para receber a bola. Em um contra-ataque é o olhar que define o posicionamento dos companheiros, daí o olhar ter um significado táctico neste jogo.

b) Linguagem das mãos: apesar de no jogo de travinha nenhum dos participantes poder pegar a bola com as mãos, estas interferem diretamente na lógica do jogo. O gesto com as mãos mais frequente é o de pedir bola. Com as mãos ele indica em que parte do seu corpo ele quer a bola (cabeça, peito, pés) ou simplesmente, num gesto "desesperado" ergue braços e mãos "dizendo" não importa em que lugar a bola venha, mas que venha.

Outro gesto significativo é o de indicar com o dedo o local onde se quer a bola, apontando para esta área, geralmente livre para atuar. Frequentemente observamos esta ação nos contra ataques, quando os companheiros sinalizam para onde a bola deverá ser lançada, geralmente, quando o número de atacantes supera o de defensores, abrindo espaços vazios na área de jogo para o ataque.

\subsubsection{CóDIGOS PRAXÊMICOS}

a) A Movimentação: Os jogadores se movimentam respeitando sempre a trajetória da bola. A ocupação espacial é comandada por aquele que conduz a bola, se ele está no centro do campo significa que esta centralizando a marcação para que os companheiros se desloquem pelas laterais. A grande maioria das jogadas feitas saem do centro para as laterais, visando utilizar todos os espaços do campo; diferente de começar as jogadas pelas laterais, em que o campo vai afunilando, fazendo com que os adversários tenham mais facilidade de obter êxito na marcação.

O que há de comum nestes tipos de movimentação (pivô, linha e alternância de posição) é que há uma intensa comunicação corporal entre os participantes. A todo o momento, os participantes se movem oferecendo possibilidades de passes e abrindo espaços na defesa adversária. Quando os três trocam de posições é sempre em um mesmo esquema, formando um "V" na frente da defesa adversária. Um jogador em cada ponta do "V", trocando de posições de forma 
a um preencher a posição do outro. "Nesta movimentação, há uma troca de passes curtos entre os jogadores para que os marcadores desloquem-se e abram espaço na área" (SAAD; COSTA, 2005, p. 81). Muitas vezes, os jogadores utilizam esta estratégia de forma espontânea, sem ter muita consciência de sua complexidade. Mas, mesmo sem ter essa consciência, eles estão operando uma estratégia motriz, quando um jogador se desloca em um sentido, o outro sabe que tem que se deslocar para preencher a posição do companheiro, poderemos assim reconhecer esta ação como um praxema utilizado pelos jogadores.

b) A Indução Corporal: Por ser uma área de jogo de pequenas dimensões, é necessário ao jogador ter velocidade e agilidade para induzir o adversário ao erro. É quando a movimentação do corpo e de uma de suas partes levar os adversários a tomarem decisões precipitadas. Um bom exemplo é o movimento no qual o jogador passa os pés por cima da bola, de modo rápido e alternado, conhecido como "pedalada", causando uma indecisão no adversário para que lado ele irá tentar passar. Na maioria das vezes, este drible é executado com o jogador conduzindo a bola em alta velocidade com apenas um marcador. Outro exemplo é o "elástico" entre participante e marcador, movimento no qual o participante, executando um gesto de muita agilidade e precisão, induz o marcador a ir pelo lado errado. Muito utilizado para se abrir um espaço para o chute.

\subsection{JOGO DO BALEADO}

Baleado/Queimada/Carimba todas são denominações usadas para esse jogo em diferentes regiões do Brasil. Como os demais jogos populares, ninguém sabe ao certo como surgiu ou quem inventou suas regras. O único esporte ao qual se assemelha é o handebol, apenas na forma de fazer passes e arremessar a bola.

O baleado observado consistia em oito jogadores de cada lado do campo, realizado numa rua de terra com uma bola de voleibol. Em que meninos e meninas de 10 a 14 anos participavam juntos no jogo. O campo media 30 metros de comprimento por 20 metros de largura, em média, com linhas que delimitavam o campo, marcadas 
na areia com o pé e remarcadas a todo instante durante o jogo. Não podia desviar-se da bola, quem desviar-se era mandado para o "mofo", e durante a bola em jogo ninguém poderia sair da área de jogo, caso alguém saísse, a equipe perderia a posse de bola. $\mathrm{O}$ objetivo era balear a todos da equipe adversária. Pela classificação de Parlebas (2001) podemos definir esse jogo como sendo um Jogo Tradicional, por ser passivo de alterações, as regras mudam segundo a vontade dos jogadores e não está relacionado diretamente a um esporte em termos de regras.

\subsubsection{Ações Motrizes de ContracomunicaçÃo}

a) Movimentação Ofensiva Adversária: as primeiras características percebidas pela equipe adversária referem-se ao braço que melhor arremessa a bola e as principais preferências de jogo, se arremessar ou combinar. Desta forma, a equipe adversária previamente já sabe o que ele vai fazer com a bola.

b) Movimentação Defensiva: enquanto a bola estiver com o time adversário, a principal preocupação é manter-se o mais longe possível da bola. A movimentação defensiva está condicionada a trajetória da bola, diferente dos outros jogos em que os jogadores buscam ficar mais próximos da bola, neste, eles fogem dos que estão de posse da bola, para reduzir as chances de ser atingido. Os jogadores, mesmo em seu espaço limitado, devem lutar pela posse de bola, tentando a interceptação e antecipação dos passes (GRECO; BENDA, 1998).

c) Protagonistas do Jogo: análise dos jogadores que tem maior capacidade de reação, são aqueles que demonstram maior agilidade ao se desviar da bola, melhor arremessam a bola e os que têm mais força e precisão no arremesso. Força e velocidade de reação são os principais atributos que caracterizam um protagonista do baleado. Procura-se também identificar os possíveis pontos fracos a serem explorados. Como dificilmente os que estão no outro lado do campo tentam segurar a bola, a estratégia motriz é desvia-se dela. 


\subsubsection{Ações Motrizes de ComunicAçÃo}

a) Passes: a maior troca de passes é efetuada a partir do momento em que algum jogador é atingido e vai para o "mofo". Este vai para o outro lado da quadra, por trás da linha de fundo que delimita o espaço de jogo da equipe adversária, tentando colaborar com seus companheiros. Só a partir deste momento é que há uma intensa troca de passes entre os companheiros, porque enfraquece o adversário fazendo-o observar e se deslocar para os dois lados da quadra.

b) Movimentação Ofensiva: enquanto não há um jogador que foi atingido, não acontece nenhuma movimentação tática significativa em termos de interação. $\mathrm{O}$ jogo só tem inicio mesmo quando a equipe está em desvantagem numérica e procura mais formas de acertar um adversário. A partir deste momento, o jogo se torna mais rápido, mais competitivo, passes pelo alto e troca rápida de passes. $\mathrm{O}$ jogo ganha outra "vida" devido a essa troca de passes entre o "mofo" e o outro lado da quadra.

\subsubsection{Códigos Gestêmicos e PraxÊmicos}

\subsubsection{CódIGOS GESTÊMICOS}

a) O Olhar: seja nos passes ou no arremesso de bola tentando acertar o adversário, o olhar se comunica (expressa, promete, anuncia). Na maioria das vezes, entre os companheiros, o olhar dá muitas pistas preciosas para os adversários: diz para quem vai ser passada a bola, de que forma - por cima ou por baixo-, e também diz qual adversário será alvejado.

b) Linguagem das mãos: além de ser fundamental para arremessar a bola e segurar os arremessos, e às vezes proteger-se deles, olhos e mãos dialogam dentro jogo, mas com apenas um significado, pedir a bola - "combina!". Também com as mãos pedem de variadas formas: erguendo-as a frente do peito, para o alto ou assinalando com os indicadores para o alto. Estes gestos são 
explícitos, já que não podem ser escondidos, eles escolhem o momento adequado em que os adversários não estão observando, mas é feito em toda jogada e diante dos adversários, faz parte da tradição deste jogo.

\subsubsection{CÓDIGOS PRAXÊMICOS}

a) A Movimentação: muitas das jogadas do baleado são feitas a partir da movimentação dos companheiros que estão no "mofo", acenando com as mãos ou balançando a cabeça, talvez seja este o jogo com maior número de gestos feitos abertamente. Já que é bem mais complicado para aqueles que estão tentando se desviar prestar atenção nos dois lados da quadra ao mesmo tempo.

b) A Indução Corporal: as principais técnicas de indução corporal feitas pelos participantes são as de fingir que vai arremessar a bola contra o adversário ou fingir que vai passar a bola para o companheiro que esta no "mofo", para isso faz toda uma contorção de tronco e braços.

\subsection{Jogo dO FUtEVÔLEI}

Analisamos o futevôlei praticado por jovens e adultos com idades entre 17 e 25 anos, que praticavam o jogo na quadra de vôlei de areia em uma praça pública. Durante o período de observação, selecionamos oito jogos, os quais foram praticados, quase pelos mesmos jogadores. Sem árbitros, com as marcações laterais e de fundo feitas na areia arrastando o pé. As linhas eram remarcadas a cada fim de jogada. Cada equipe não podia dar mais do que três toques na bola. Sendo dois jogadores para cada lado. Vencia quem alcançasse 15 pontos primeiro. Foi observado por duas vezes que a rede havia sido substituída por uma única corda amarrada no ponto mais alto dos postes, está foi a única alteração permitida que foi presenciada durante os jogos.

Diferente da Travinha ou Baleado, o futevôlei tem uma permanência das regras (campo, jogadores, duração, implemento) e no Brasil, desde sua criação 1965, já é praticado de modo organizado 
em campeonatos nacionais e internacionais. É um jogo cuja esportivização se encontra muito adiantado em termos de Federação Nacional de Futevôlei (Brasil). Não é uma modalidade olímpica, mas por ser praticada em muitos outros países da América Latina, Europa, Ásia e Estados Unidos possui uma Federação Internacional de Futevôlei. Caracterizando-se, portanto, no que Parlebas (2001) define como um Quase Esporte, por se constituir num jogo semiinstitucionalizado cuja regulamentação não conseguiu status internacional de maneira inquestionável. Adotamos essa classificação, mesmo reconhecendo a flexibilidade com que o jogo era praticado na praça pública, sua gratuidade e sua finalidade de lazer, mas sabemos por Parlebas (2001, p.51) que "as situações ludomotrizes oferecem dificuldades na hora da classificação".

\subsubsection{Ações Motrizes de Contracomunicação}

a) Movimentação ofensiva adversária: A partir do momento em que se faz o saque e começa o jogo com a bola de posse da equipe adversária, ocorre o inicio de todo um processo de análise das ações feitas pelos jogadores: qual a perna ou parte do corpo que o jogador tem mais facilidade de tocar na bola? A altura dos adversários? Se são bons de recepção, levantamento ou finalização? Em qual fundamento eles têm mais dificuldades? Tudo isto é observado pela equipe adversária já nos primeiros toques de bola, e conscientemente, estas perguntas são feitas na mente de cada um. É o primeiro nível de análise da disposição no espaço de jogo da equipe adversária e as respectivas funções de cada jogador oponente (ARAÚJO; RIBAS, 2008).

b) Movimentação Defensiva: Os jogadores se posicionam de forma a ocupar todos os espaços do campo de jogo, mais centralizados nem tão distantes ou muito próximos um do outro. Este comportamento consiste numa estratégia motriz para se interpor as ações da equipe adversária. É uma movimentação de oposição em relação aos espaços, visto estarem pensando no melhor posicionamento para se o'por as jogadas adversárias (PARLEBAS, 2001, p. 100). A ocupação dos espaços visa a melhor intercepção da 
bola, pois ao deixar espaços vazios na quadra facilitaria a jogada do adversário, colocando-os em situação difícil para defender. Assim, neste jogo todas as ações e posições dos jogadores estão condicionadas pelo parâmetro situacional, que abrange tempo-espaçosituação, conforme a trilogia nomeada por Greco e Brenda (1998). Essa ocupação dos espaços vai sendo aprendida no decorrer do jogo, ou seja, devido aos ataques eles passam a tomar consciência de que não devem ficar muito próximos à rede e nem muito longe dela, e que certa proximidade entre os companheiros proporciona uma ajuda possível no ataque, o que chamam de "fazer a cobertura".

c) Protagonistas do Jogo: É o jogador mais requisitado para atacar, levantar ou recepcionar a bola, identificando as suas melhores qualidades em termos técnicos e tácticos."Cabe aos jogadores identificar quem são os jogadores com essa competência" (ARAÚJO; RIBAS, 2008, p. 1). Quando é identificado, este jogador passa a ser ignorado dentro do jogo para limitar as suas ações. Ele não é mais solicitado para recepcionar a bola, já que o jogo consiste em só poder tocar na bola por no máximo três vezes, ele fica restrito a apenas preparar o ataque do companheiro ou passar a bola à equipe adversária.

\subsubsection{AçõEs Motrizes de COMUNICAÇÃO}

a) Passes: Esta é uma ação muito variável entre os participantes, foi observado que irá depender do nível de habilidade de cada um. Os jogadores fazem uso de pernas, cabeça e peito para passar à bola, preferem o passe com o pé por terem mais facilidade com o futebol, reduzindo desta forma, a probabilidade de erro. Sempre quando se usava o peito e cabeça para se passar a bola, os erros eram freqüentes: passes com direção errada, altos ou baixos demais, pouca ou muita força, caracterizando uma má recepção (GRECO; BENDA, 1998).

b) Movimentação Ofensiva: Em uma ação ofensiva, os participantes procuram não se distanciar muito um do outro para que não haja muita dificuldade na hora da troca de passes. Ao se 
manterem próximos, estes se arriscam em jogadas mais rápidas, fazendo uso de diferentes membros do corpo, não se reduzindo apenas ao uso dos pés.

\subsubsection{Códigos Gestêmicos e Praxêmicos}

\subsubsection{CódIGOS GESTÊMICOS}

a) O Olhar: O jogo de futevôlei requer do participante um elevado domínio de diferentes capacidades quase que simultaneamente, coordenação, acuidade visual, uso da força e equilíbrio. A troca de olhares táticos é fundamental durante o jogo, é uma forma de executar as jogadas mais seguras para o companheiro, fazendo com que o adversário tenha menos chances de interceptar a ação. $\mathrm{O}$ mestre dos gestemas e praxemas é o levantador, aquele que faz o último passe, antes da conclusão da jogada. Não se sabe ao certo o que vai fazer aquele que prepara a jogada para o toque final, isto irá depender da qualidade da bola que ele está recebendo, do posicionamento do companheiro e do posicionamento dos adversários. Mesmo antes de a bola estar em seu campo de jogo o levantador colocando as mãos para trás gesticula com os dedos onde ele quer receber a bola ou se vai passar de segunda.

Para se efetuar uma cabeçada ao fundo da quadra ou um chute próximo à rede, é necessário um excepcional senso de direção espacial, calculado antecipadamente pelo olhar do atacante. O olhar diz a direção e a força, pela forma com que o jogador olha para a bola e para o campo de jogo, e isto não é algo exclusivo do futevôlei, mas em diversos jogos e esportes coletivos em que há a presença do olhar tático, definindo as ações do jogo.

b) Linguagem das mãos: a estratégia motriz de cada equipe inicia-se antes de cada saque, em que os participantes indicam com os dedos, escondendo-os nas costas, o espaço onde a bola deve ser jogada e em qual jogador deverá ser executado o saque. É importante 
ressaltar que as formas e significados destes gestos variam de jogador para jogador, cada um tem o seu jeito preferido de gesticular para os companheiros.

\subsubsection{CódIGOS PRAXÊMICOS}

a) A Movimentação: toda a movimentação do futevôlei já está pré-determinada pelos companheiros antes mesmo de estar com a bola no seu campo de jogo. $\mathrm{O}$ futevôlei não permite que o jogador pense por muito tempo, já que ele só pode tocar apenas uma vez na bola. $\mathrm{O}$ pensamento é rápido e condicionado pela trajetória da bola.

Os jogadores de defesa tendem a se movimentar de forma diferente durante o jogo. Ao recepcionar a bola, se posicionam um mais próximo à rede e outro mais próximo ao fundo. Já durante um ataque, os jogadores defensivos se posicionam mais ao fundo. A movimentação de um jogador atua como um sinal tático, para o companheiro, um praxema inconsciente, por exemplo, quando um jogador se desloca para interceptar uma bola que cai junto à rede, $\mathrm{o}$ companheiro analisa e busca uma melhor forma de se posicionar para dar sequência à jogada.

b) A Indução Corporal: o levantador é o jogador chave no momento de um ataque, porque ao dar direção ele induz não apenas o adversário, mas também o companheiro. Os jogadores que fazem a conclusão da jogada através dos pés e cabeça, induzem os adversários a seguir direções contrárias à bola, eles direcionam a cabeça para um lugar e tocam na outra direção; fazem uma expressão facial e corporal de colocar uma bola forte ao fundo e na última hora tocam devagar junto a rede, estes são exemplos de como os praxemas interferem e determinam uma ação de jogo.

\section{Considerações FinaIS}

Observamos que o desempenho de uma equipe é determinado pela comunicação estabelecida internamente na equipe e pela antecipação da jogada adversária. Pela capacidade de disfarce para 
que a equipe oponente não descubra seus signos, e pela decifração dos signos dos adversários, fazendo as análises antecipadas e situacionais. Assim, tornamos visível a riqueza cognitiva, motora e social destes jogos praticados popularmente nos bairros de João Pessoa/PB, bem como em todo território brasileiro.

Destacamos algumas aprendizagens sociais e cognitivas, apenas para ilustrar. Social: Vimos os moradores ocuparem os espaços públicos (rua, praça e terreno baldio) tornando-os espaços de convivência. Em lugar dos medos sociais, das ruas e descampados como lugares da desconfiança, devido ao crime (DA MATA, 1997, p. 98), crianças, jovens e adultos fazem a apropriação destes vazios urbanos como lugar de lazer e de experiências culturais. Há também as aprendizagens de negociação, tanto dos espaços quanto nos jogos. O jogo de travinha acontecia num lugar fronteiriço entre dois bairros, por isso os usuários haviam construído um código interno rigoroso, determinação de dias para cada um dos bairros. Essa negociação também era dada na flexibilização das regras (travinha e baleado) para caber todos os jogadores desejosos de participar, de conduzir o jogo sem proporcionar vantagem para nenhuma das equipes. A negociação nos ajustes das regras por meio de verbalizações proporciona a aprendizagem da convivência porque proporciona certa estabilidade emocional aos jogadores, além de estar estimulando as capacidades criativas e reflexivas. Além destas, ao jogar o brincante aprende a assumir diferentes papeis sociais (BROUGÉRE, 1998); no baleado, por exemplo, ora ele possui "vida" ora está no "mofo"; ou na travinha, ora ele é pivô ora é ala.

Aprendizagem Cognitiva: Nestes três jogos vimos as exigências cognitivas para a realização de cada jogo, estratégias ofensivas e defensivas, análise situacional ou gestual dos adversários, conhecimento técnico-tático da modalidade, análise antecipada dos atacantes e tomada de decisões. Podemos perceber que no Futevôlei, por exemplo, os movimentos preparatórios defensivos ocorrem mesmo antes da bola estar em jogo, os adversários identificam com maior rapidez os protagonistas do jogo bem como os que têm menos habilidade. Já na travinha e no baleado, as primeiras ações de 
contracomunicação acontecem nos primeiros contatos do adversário com a bola. Em todos os jogos há muita troca de passes, mesmo sendo com um número limitado no futevôlei, pois o objetivo é tomar o adversário de surpresa, seja na colocação da bola no espaço, seja no gol, seja em balear/queimar o outro.

Na comunicação direta olhos e gestos manuais tornam-se signos motrizes, pois estão enraizados na prática corporal destes jogos. São ações corporais não opcionais, mas fazem parte da cultura do jogo, de forma que participar de qualquer uma destas modalidades haverá de utilizar estes códigos, de interpretar os códigos alheios e (re)significá-los, portanto, de adquirir sua linguagem, sua cultura (GOMES-DA-SILVA, 2011). Sendo assim, estas diferentes interações de cooperação e oposição, gestemas e praxemas, muitas vezes, insignificantes para quem assiste ou impensadas para quem participa do jogo, mas para um professor ou técnico se constitui numa rica ferramenta de análise para formulação de situações de ensino e de treino para diferentes públicos (crianças, adolescentes, jovens e adultos). De modo que neste estudo constatamos o relevante papel da Praxiologia Motriz na organização do espaço pedagógico do professor no ensino dos jogos tradicionais ou semiinstitucionalizado.

Diante desta compreensão sugerimos que a inclusão curricular das análises aqui trazidas à tona sirvam de apoio prático ao professor para priorização de objetivos, sequencia dos conteúdos, orientações metodológicas e instrumentos de avaliação, tudo a partir da lógica interna da atividade proposta, sua estrutura e dinâmica (apud MORENO; RODRIGUES RIBAS, 2003). Assim poderia promover uma prática de atividades que requer um maior grau de antecipação de jogadas (se esse for o objetivo), ou melhorar a comunicação entre os companheiros, praticando atividades de gestualidade, ou ainda numa perspectiva de leitura das ações adversárias, agindo em torno das dificuldades e falhas da equipe oponente.

Pensamos assim, por entendermos a educação física escolar como a pedagogia das situações de movimento, ou seja, como "uma prática de intervenção que influi nas condutas motrizes dos 
participantes em função de normas educativas implícitas ou explícitas" (PARLEBAS, 2001, p. 172). Por isso, afirmamos que os resultados desta pesquisa podem auxiliar o professor a dar um novo enfoque pedagógico em suas aulas, visto que as ações motrizes, ou as situações de enfrentamento codificado, favorecem ao ensino de jogos mais conscientes dos seus significados culturais, lógicos e motores. Os currículos de formação básica podem propor o ensino destes jogos como conteúdo motriz para o Ensino Fundamental II e Ensino Médio, como, semelhantemente, Santos e Blanco (2004) propuseram a unidade didática dos jogos tradicionais, em Burgo-Espanha. Ou como foi estruturado o Desenho Curricular da Educação Física pela Direção Geral da Educação em Buenos Aires-Argentina (ZYSMAN; PAULOZZO, 2006).

Por fim, destacamos que o resultado desta pesquisa nos aponta para dois desdobramentos socioeducativos. Primeiro, os jogos praticados por crianças e jovens, de modo espontâneo e autoorganizado, sem a intervenção do adulto ou da institucionalização esportiva, nos vazios urbanos, são possuidores de uma riqueza sociocultural. Ou seja, a prática destes jogos não é da ordem da inutilidade, pois eles requerem de seus praticantes inteligência, capacidade expressiva, desenvoltura motriz e conhecimento cultural. Daí a importância de políticas públicas que valorizem as situações ludomotrizes investindo nos espaços de prática esportiva na cidade. Segundo, os jogos tradicionais, devido sua popularidade e possibilidade de flexibilização de regras, negociação dos conflitos, adaptações ao espaço-jogadores-implemento, revelam o quanto estes jogos poderiam estar sendo valorizados pelos professores de educação física na escola como fonte de informação para construir conhecimentos sobre cidadania, em termos de participação social e política, responsabilidade ética e civil de solidariedade e cooperação; bem como, ser fonte para ensinar a apreciar criticamente a própria cultura de movimento em contraponto à cultura esportiva midiática. Por tudo isso, recomendamos a valorização dos jogos tradicionais pela educação física escolar. 
Communication motriz in popular games: a praxiológica analysis

Abstract: This article aims from the Praxiologia Motriz, reveal the different interactions (communication, contracomunicação, gestemas and praxemas) present in sociomotrizes popular games, practiced on the streets and squares in the city of João Pessoa-PB. In this study, the game reveals itself as an act of human communication through body actions of the players who create and maintain a complex system of interaction, revealing itself as a source of learning body language, cognitive strategies and cultural experience.

Key words: Traditional games. Communication. Praxiologia Motriz.

Comunicación motriz en juegos populares: un
análisis praxiológica
Resumen: Este artículo tiene como objetivo de la
praxiología motriz, ponen de manifiesto las diferentes
interacciones (comunicación, contracomunicaçión
gestemas y praxemas) presentes en sociomotrizes
juegos populares, practicados en las calles y plazas
de la ciudad de João Pessoa-PB. En este estudio, el
juego se revela como un acto de comunicación humana
a través de las acciones del cuerpo de los jugadores
que crean y mantienen un sistema complejo de
interacción, que se revela como una fuente de
aprendizaje del lenguaje corporal, estrategias
cognitivas y la experiencia cultural.
Palabras-clave: Juegos tradicionais.Comunicación.
Praxiología Motriz.

\section{REFERÊNCIAS}

ARAÚJO, Pablo Aires; RIBAS, João Francisco Magno. A primeira linha de defesa no voleibol: o bloqueio. Revista Digital EFdeportes, Buenos Aires, v. 13, n. 124. set. 2008. Disponível em: <http://www.efdeportes.com/efd124/a-primeira-linha-dedefesa-no-voleibol-o-bloqueio.htm>. Acesso em: abr. 2011.

BROUGÉRE, G. Jogo e educação. Porto Alegre: Artes Médicas, 1998.

DAMATA, R. A casa e a rua: espaço, cidadania, mulher e morte no Brasil. Rio de Janeiro: Rocco, 1997.

Movimento, Porto Alegre, v. 18, n. 03, p. 159-182, jul/set de 2012. 
ELLOUMI, Ali; PARLEBAS, Pierre. Análise sociocultural dos jogos esportivos tradicionais tunisianos. Fitness Performance Journal, Rio de Janeiro, v. 8, n. 2, p. 136-145, mar./abr. 2009.

GALEANO, Eduardo. Futebol ao sol e a sombra. 3. ed. Porto Alegre. LePM, 2008.

GOMES-DA-SILVA, Pierre Normando. A cultura do jogo e o jogo da cultura: por uma semiótica da corporeidade. João Pessoa: Ed. Universitária UFPB, 2011.

GRECO, Pablo Juan; BENDA, Rodolfo Novellino (Org.). Iniciação esportiva universal. Belo Horizonte: Ed. UFMG, 1998. v. 2.

MORENO, J.H.; RODRIGUES RIBAS, J. Los contenidos y objetivos exclusivos del currículo de educación física escolar desde lapraxiologia motriz: lós casos de laeducación secundaria obligatoria em España. Revista de Educación Física, A Corunã, n. 90, p. 11-23, 2003.

OLIVEIRA, Gil Teixeira; RIBAS, João Francisco Magno. Articulações da praxiologia motriz com a concepção crítico-emancipatória. Movimento, Porto Alegre, v. 16. n. 1, p. 131-148, jan./mar. 2010.

PARLEBAS, Pierre. Juegos, deporte y sociedad: léxico de praxiología motriz. Barcelona: Paidotribo, 2001.

RIBAS, João Francisco Magno (Org.). Jogos e esportes: fundamentos e reflexões da praxiologia motriz. Santa Maria: Ed. UFSM, 2008.

SAAD, Michél; COSTA, Claiton. Futsal: movimentações defensivas e ofensivas. 2. ed. Florianópolis. Visual Books, 2005.

SANTOS, R.M; BLANCO, F.J. Praxiologia motriz y educación física: uma unidad didática de juegostradicionales em secundaria obligatoria. EFDeporte, Buenos Aires, v. 1, n. 1, p. 11-16, nov./dic. 2004.

ZYSMAN, A.; PAULOZZO, M. (Coord.) Diseño curricular para laeducación secundaria. 1a ano. La Plata: Dir. General de cultura y educación de La província de Buenos Aires, 2006. Disponível em: <http://abc.gov.ar/lainstitucion/organismos / consejogeneral/disenioscurriculares/documentosdescarga/secundaria1anio.pdf $>$.

Endereço para correspondência:

Leys Eduardo dos Santos Soares

Rua Alipio da Cunha Machado, 1643 - Rangel

João Pessoa/PB. CEP: 58070-150

Recebido em: 23.03.2012

Aprovado em: 10.09.2012 
